\title{
Synthesis and characterization of spherical and rod like nanocrystalline $\mathrm{Nd}_{2} \mathrm{O}_{3}$ phosphors
}

\author{
B. Umesh ${ }^{\mathrm{a}, \mathrm{b}}$, B. Eraiah ${ }^{\mathrm{b}}$, H. Nagabhushana ${ }^{\mathrm{c}, *}$, B.M. Nagabhushana ${ }^{\mathrm{d}}$,

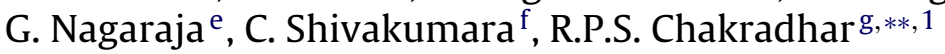 \\ a Department of Humanities, PVP Polytechnic, Dr. AIT Campus, Bangalore 560056, India \\ ${ }^{\mathrm{b}}$ Department of Physics, Bangalore University, Bangalore 560 056, India \\ ' Advanced Materials Research Laboratory, University college of Science, Tumkur University, Tumkur-572103, India \\ ${ }^{\mathrm{d}}$ Department of Chemistry, M.S. Ramaiah Institute of Technology, Bangalore 560 054, India \\ e Department of Inorganic \& Physical Chemistry, Indian Institute of Science, Bangalore 560 012, India \\ f Solid State and Structural Chemistry Unit, Indian Institute of Science, Bangalore 560 012, India \\ g Glass Technology Laboratory, Central Glass and Ceramic Research Institute (CSIR), Kolkota 700032,India
}

\section{A R T I C L E I N F O}

\section{Article history:}

Received 1 February 2010

Received in revised form

22 September 2010

Accepted 25 September 2010

Available online 1 October 2010

\section{Key words:}

Phosphors

$\mathrm{Nd}_{2} \mathrm{O}_{3}$ : SEM

TEM

Raman

XRD

Optical properties

\begin{abstract}
A B S T R A C T
Spherical and rod like nanocrystalline $\mathrm{Nd}_{2} \mathrm{O}_{3}$ phosphors have been prepared by solution combustion and hydrothermal methods respectively. The Powder X-ray diffraction (PXRD) results confirm that hexagonal A-type $\mathrm{Nd}_{2} \mathrm{O}_{3}$ has been obtained with calcination at $900{ }^{\circ} \mathrm{C}$ for $3 \mathrm{~h}$ and the lattice parameters have been evaluated by Rietveld refinement. Surface morphology of $\mathrm{Nd}_{2} \mathrm{O}_{3}$ phosphors show the formation of nanorods in hydrothermal synthesis whereas spherical particles in combustion method. TEM results also confirm the same. Raman studies show major peaks, which are assigned, to $\mathrm{F}_{\mathrm{g}}$ and combination of $A_{\mathrm{g}}+E_{\mathrm{g}}$ modes. The PL spectrum shows a series of emission bands at $\sim 326-373 \mathrm{~nm}$ (UV), $421-485 \mathrm{~nm}$ (blue), $529-542 \mathrm{~nm}$ (green) and $622 \mathrm{~nm}$ (red). The UV, blue, green and red emission in the PL spectrum indicates that $\mathrm{Nd}_{2} \mathrm{O}_{3}$ nanocrystals are promising for high performance materials and white light emitting diodes (LEDs).
\end{abstract}

(c) 2010 Elsevier B.V. All rights reserved.

\section{Introduction}

Neodymium oxide $\left(\mathrm{Nd}_{2} \mathrm{O}_{3}\right)$ is widely used in various applications such as luminescent materials, catalyst for automotive industry, UV absorbent, glass-polishing material and protective coatings [2-4]. Rare earth sesquoxides exist in three different structural types depending on the ionic radii of the rare earth ion. Those with larger cations form hexagonal (A-type) with seven coordinated polyhedron while those with smaller cations form cubic lattice (C-type) with both seven and six coordinated polyhedron in the ratio of $2: 1$ [1].

Literature survey reveals that most of the phosphor materials are produced by high temperature solid state synthesis and having low surface area, large particle size, inhomogeneous, presence of large defects, which are harmful to luminescence [5]. All

\footnotetext{
* Corresponding author. Tel.: +919620230702.

** Corresponding author.

E-mail addresses: bhushanvl@rediffmail.com (H. Nagabhushana), sreechakra72@yahoo.com, chakra72@gmail.com (R.P.S. Chakradhar).

1 Scientist, CSIR-NAL, Bangalore 560 017, india.
}

the above-mentioned problems can be mitigated by the use of wet chemical methods (combustion and hydrothermal). Solution combustion is one of the wet chemical methods, which produces nano sized powder using an exothermic reaction between metal nitrates and an organic fuel. This method has several advantages including process simplicity, high purity and cheap sources; besides the desired product can be prepared in large scale in nanometer size [6-8]. On the other hand, in hydrothermal synthesis, an aqueous solvent is used as a reaction medium, which is environmentally friendly and the reaction is carried out in a closed system. Powders with different microstructure, morphology and phase composition can be obtained in hydrothermal method by varying parameters such as temperature, pressure, duration of process, concentration of chemical species, concentration of solution and $\mathrm{pH}$ of solution [9-11]. Nano sized $\mathrm{Nd}_{2} \mathrm{O}_{3}$ have been prepared by various methods, such as sol-gel [12], hydrothermal synthesis [13], micro emulsion [14], sol-gel auto combustion [15]. Hardly any work has been carried out on solution combustion and hydrothermally prepared $\mathrm{Nd}_{2} \mathrm{O}_{3}$ phosphor materials [16]. We report here results of the structure, microscopy and spectroscopy studies on spherical and rods like nanocrystalline $\mathrm{Nd}_{2} \mathrm{O}_{3}$ 


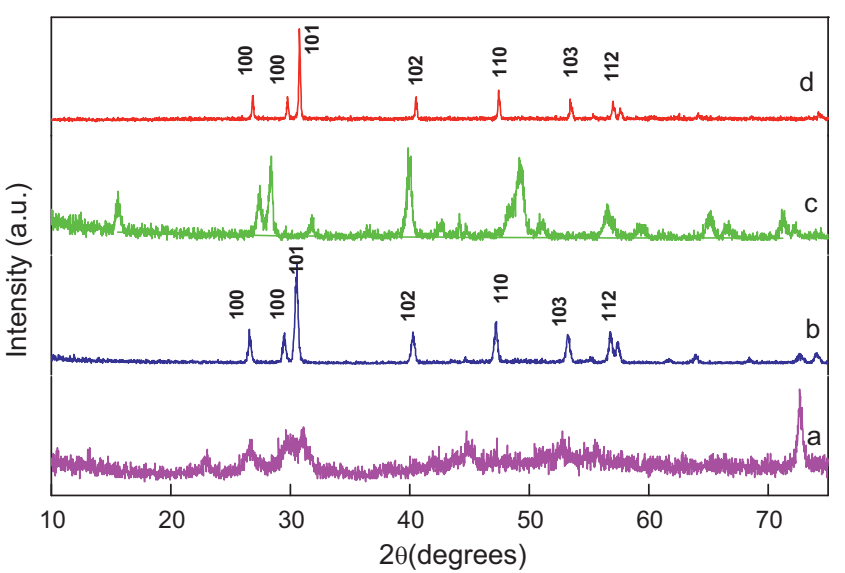

Fig. 1. PXRD patterns of $\mathrm{Nd}_{2} \mathrm{O}_{3}$ (a) as formed (combustion synthesis); (b) calcinated at $900{ }^{\circ} \mathrm{C}$ (combustion synthesis); (c) as-formed (hydrothermal synthesis) and (d) calcinated at $900^{\circ} \mathrm{C}$ (hydrothermal synthesis).

phosphors prepared by solution combustion and hydrothermal methods.

\section{Experimental}

\subsection{Synthesis of $\mathrm{Nd}_{2} \mathrm{O}_{3}$ nano phosphors}

An aqueous solution containing stoichiometric amounts of analar grade neodymium nitrate $\left(\mathrm{Nd}\left(\mathrm{NO}_{3}\right)_{3}\right)$ and oxalyl dihydrazide $\left(\mathrm{C}_{2} \mathrm{H}_{6} \mathrm{~N}_{4} \mathrm{O}_{2} ; \mathrm{ODH}\right)$ fuel were dissolved in a minimum quantity of doubled distilled water in a cylindrical Petri dish of approximate $150 \mathrm{ml}$ capacity. ODH was used as a fuel in the combustion synthesis and it is prepared in our laboratory by the reaction of diethyl oxalate and hydrazine hydrate as described in the literature [17]. The mixture was dispersed well using a magnetic stirrer for about $5 \mathrm{~min}$. A Petri dish containing the heterogeneous mixture was placed in a pre-heated muffle furnace maintained at $400 \pm 10^{\circ} \mathrm{C}$. The reaction mixture initially undergoes thermal dehydration followed by ignition with liberation of large gaseous products such as oxides of nitrogen and carbon. Finally, a voluminous and foamy greenish product has been obtained.

Theoretical equation assuming complete combustion of the redox mixture used for the synthesis of $\mathrm{Nd}_{2} \mathrm{O}_{3}$ phosphor may be written as:

$2 \mathrm{Nd}\left(\mathrm{NO}_{3}\right)_{3}+\mathrm{C}_{2} \mathrm{H}_{6} \mathrm{~N}_{4} \mathrm{O}_{2} \rightarrow \mathrm{Nd}_{2} \mathrm{O}_{3}+2 \mathrm{CO}_{2}+10 \mathrm{~N}_{2}+3 \mathrm{H}_{2} \mathrm{O}$

In the hydrothermal synthesis, $\mathrm{Nd}_{2} \mathrm{O}_{3}$ was dissolved in $1: 1 \mathrm{HNO}_{3}$ and heated on a sand bath to obtain a clear solution. The aqueous $\mathrm{NaOH}(1 \mathrm{~N})$ solution was added drop wise until the $\mathrm{pH}$ is adjusted to 11 . The solution was transferred in a stainless steel autoclave of about $60 \mathrm{ml}$ capacity and kept in an oven maintained at $200{ }^{\circ} \mathrm{C}$ for $24 \mathrm{~h}$. After $24 \mathrm{~h}$ the autoclave was taken out from the oven and cooled to room temperature. A white solid product was deposited at the bottom of the autoclave. This white solid product has been collected by filtration, washed with distilled water and alcohol several times and then dried at $80^{\circ} \mathrm{C}$. The final product obtained in both the methods was further heat treated at $900^{\circ} \mathrm{C}$ for $3 \mathrm{~h}$ and used for characterization.

\subsection{Instruments used}

The powder X-ray diffraction studies have been carried out using Phillips X-ray diffractometer (model PW 3710) with CuK $\alpha$ radiation $(\lambda=1.5405 \AA ̊)$. The average crystallite size $(d)$ was calculated from the diffraction line width based on Scherer's formula $d=0.9 \lambda / \beta \cos \theta$, where $\lambda$ is the wavelength of $\mathrm{X}$-rays and $\beta$ is the full width at half maximum (FWHM). The surface morphology of the samples has been examined using Scanning electron microscopy (JEOL JSM 840A) by sputtering technique with gold as covering contrast material. Transmission Electron Microscopy (TEM) analysis was performed on a Hitachi H-8100 (accelerating voltage up to $200 \mathrm{kV}, \mathrm{LaB}_{6}$ filament) equipped with EDS (Kevex Sigma TM Quasar, USA). The UV-vis spectra were recorded on a UV-3101 Shimadzu Visible spectrometer. The photoluminescence studies have been were carried out using a Perkin-Elmer LS-55 luminescence spectrophotometer equipped with Xe lamp (excitation wavelength $250 \mathrm{~nm}$ ). Raman spectroscopic studies were performed on Renishaw In-via Raman spectrometer with $633 \mathrm{~nm}$ He-Cd laser and a Leica DMLM optical microscope equipped with $50 \times$ objective, thus providing a laser spot of $2 \mu \mathrm{m}$ in diameter.

\section{Results and discussion}

Fig. 1a shows PXRD pattern of as-formed $\mathrm{Nd}_{2} \mathrm{O}_{3}$ combustion product, which shows amorphous $\mathrm{Nd}_{2} \mathrm{O}_{3}$ phase along with

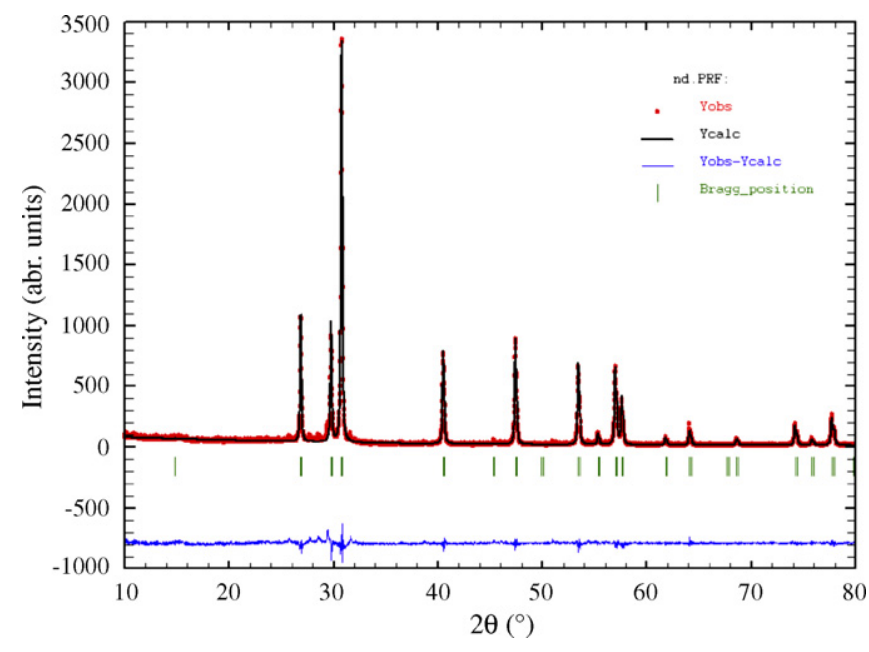

Fig. 2. Rietveld refinement of $\mathrm{Nd}_{2} \mathrm{O}_{3}$.

neodymium oxide carbonate $\left(\mathrm{Nd}_{2} \mathrm{O}_{2} \mathrm{CO}_{3}\right)$ peaks. The $2 \theta$ peaks at $22.9^{\circ}, 26.6^{\circ}, 31.1^{\circ}$ and $72.6^{\circ}$ correspond to $\mathrm{Nd}_{2} \mathrm{O}_{2} \mathrm{CO}_{3}$ (JCPDS No. 37-0806). The $2 \theta$ peaks at $\sim 29.7^{\circ}, 47.0^{\circ}$ and $53.0^{\circ}$ correspond to $\mathrm{Nd}_{2} \mathrm{O}_{3}$ (JCPDS No. 24-0779). Further a few weak unidentified impurity peaks at $44.7^{\circ}$ and $55.6^{\circ}$ have been observed. After heat treatment at $900^{\circ} \mathrm{C}, 3 \mathrm{~h}$, the PXRD-pattern of combustion-derived product has been changed to hexagonal phase with A-type of $\mathrm{Nd}_{2} \mathrm{O}_{3}$ (Fig. 1b) along with weak impurity peaks at $44.7^{\circ}$ and $55.6^{\circ}$. The hexagonal phase diffraction peaks are readily indexed with JCPDS file No. 83-1353. The formation of $\mathrm{Nd}_{2} \mathrm{O}\left(\mathrm{CO}_{3}\right)_{2}$ phase might be due to the reaction between neodymium oxide and $\mathrm{CO}_{2}$ produced at the elevated temperature during combustion reaction.

$\mathrm{Nd}_{2} \mathrm{O}_{3}+\mathrm{CO}_{2} \rightarrow \mathrm{Nd}_{2} \mathrm{O}\left(\mathrm{CO}_{3}\right)_{2}$

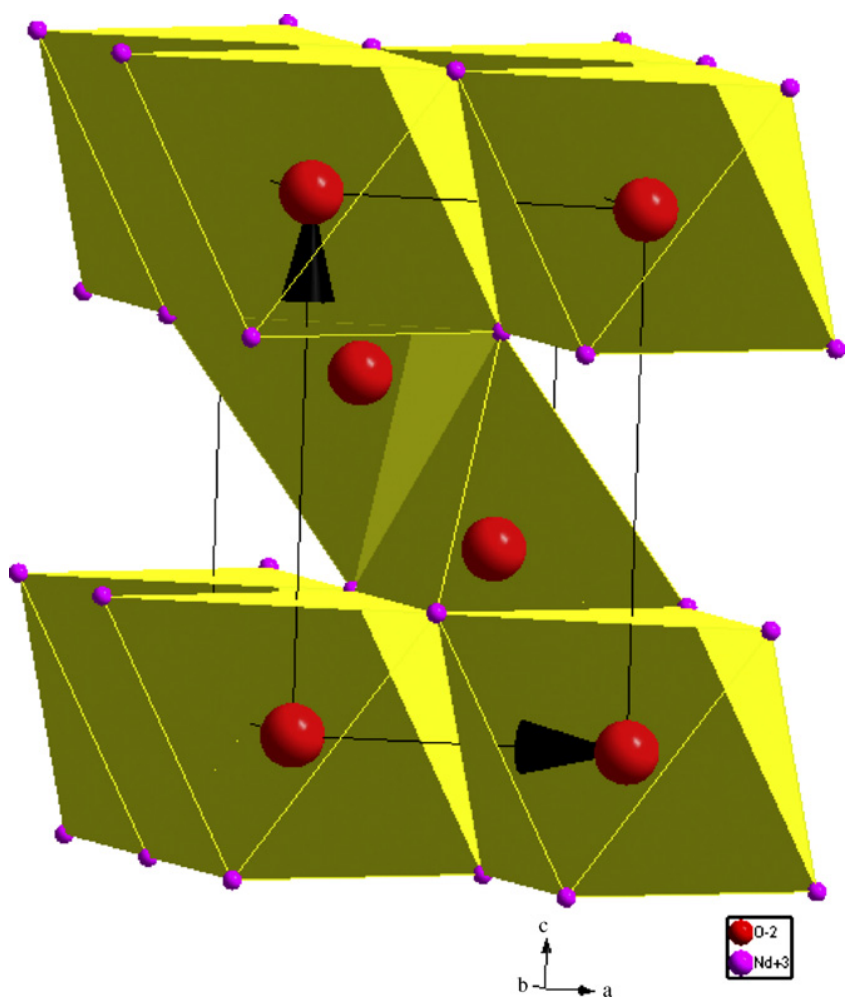

Fig. 3. Packing diagram of $\mathrm{Nd}_{2} \mathrm{O}_{3}$. 
Table 1

Rietveld refinement results and atomic co-ordination employed to model the $\mathrm{Nd}_{2} \mathrm{O}_{3}$ unit cell.

\begin{tabular}{|c|c|c|c|c|c|c|}
\hline Atom & Oxidation state & Wyckoff notation & $x$ & $y$ & $z$ & Occupancy \\
\hline $\mathrm{Nd}$ & +3 & $2 d$ & 0.3333 & 0.6666 & $0.2494(8)$ & 1 \\
\hline $\mathrm{O} 2$ & -2 & $1 \mathrm{~d}$ & 0.0000 & 0.0000 & 0.0000 & 1 \\
\hline 01 & -2 & $2 d$ & 0.3333 & 0.6666 & $0.6496(9)$ & 1 \\
\hline
\end{tabular}

System: hexagonal; space group: P-3m1 (No. 164); $a=3.8312(1), c=6.0017(3), V=76.29(7) ; R_{\mathrm{Bragg}}=4.15, R_{\mathrm{p}}=10.5, R_{\mathrm{wp}}=15.4, R_{\mathrm{F}}=3.08, \chi^{2}=1.64$.

Fig. 1c shows X-ray diffraction pattern of as-formed hydrothermal product with impurity peaks of $\mathrm{Nd}(\mathrm{OH})_{3}$ (JCPDS No. 06-0601), $\mathrm{Nd}_{2} \mathrm{OCO}_{3}$ (JCPDS No. 40-0777, 24-0781, 25-0567) and $\mathrm{Nd}_{2} \mathrm{CO}_{3}$ (JCPDS No. 30-0851). After heat treatment at $900^{\circ} \mathrm{C}$ for $3 \mathrm{~h}$, the characteristic peaks of A- $\mathrm{Nd}_{2} \mathrm{O}_{3}$ (Fig. 1d) were observed. According to the literature hexagonal neodymium oxide is observed after heat treatment at $900^{\circ} \mathrm{C}$. Fig. 2 shows the Rietveld refinement performed on the combustion synthesized nanocrystalline $\mathrm{Nd}_{2} \mathrm{O}_{3}$ heat treated at $900^{\circ} \mathrm{C}$ for $3 \mathrm{~h}$. The Rietveld refinement is a method in which the profile intensities obtained from step-scanning measurements of the powders allow to estimating an approximate structural model for the real structure. This was performed with a FULLPROF program $[18,19]$. We utilize the pseudo-voigt function in order to fit the several parameters to the data point: one scale factor, one zero shifting, four back ground, three cell parameters, five shape and width of the peaks, one global thermal factor and two asymmetric factors. A typical analysis of the sample is shown in Fig. 2 which presents the experimental and calculated XRD patterns obtained by the refinement of $\mathrm{Nd}_{2} \mathrm{O}_{3}$ phase. Fig. 3 shows the packing diagram of $\mathrm{Nd}_{2} \mathrm{O}_{3}$ after Rietveld refinement. The refined parameters such as occupancy, atomic functional positions are listed in Table 1 . The fitting parameters $\left(R_{\mathrm{p}}, R_{\mathrm{wp}}\right.$ and $\left.\chi^{2}\right)$ indicate a good agreement between the refined and observed XRD patterns for the A-type $\mathrm{Nd}_{2} \mathrm{O}_{3}$. The refined lattice parameter values $a=3.8312(1)\left(\mathrm{A}^{0}\right) ; \mathrm{c}=6.0017(3)\left(\mathrm{A}^{0}\right)$ and cell volume $76.29(7)\left(\mathrm{A}^{0}\right)^{3}$ confirm that the $\mathrm{Nd}_{2} \mathrm{O}_{3}$ has a hexagonal structure.
Fig. 4 shows the surface morphology of $\mathrm{Nd}_{2} \mathrm{O}_{3}$ as formed and heat treated at $900{ }^{\circ} \mathrm{C}, 3 \mathrm{~h}$ powders. The SEM micrograph of the as formed combustion synthesized product shows the particles are foamy, agglomerated, crispy and porous. This porous in nature is typical of combustion synthesized powders due to rapid release of gaseous by-products during combustion synthesis. These porous powders are highly friable which facilitates easy grinding to obtain finer particles [20]. After heat treatment at $900{ }^{\circ} \mathrm{C}$ for $3 \mathrm{~h}$, the particles observed to be spherical in shape with smooth surfaces. In hydrothermal method the as formed product shows nano rods with irregular shape having sharp tips. Upon heat treatment at $900{ }^{\circ} \mathrm{C}$ for $3 \mathrm{~h}$, rods having uniform thickness, smooth surfaces having length of several tens of micrometers have been obtained. Fig. 5(a) and (b) shows TEM images of $\mathrm{Nd}_{2} \mathrm{O}_{3}$ phosphor synthesized by combustion and hydrothermal methods. In combustion synthesized powders, the particles are spherical in shape and essentially consist of different sizes varying from 20 to $100 \mathrm{~nm}$. These spherical shaped particles are easy to be packed densely so that screen and displays can obtain high definition and these dense packed small particles can prevent the phosphor from aging [21]. In hydrothermal synthesized $\mathrm{Nd}_{2} \mathrm{O}_{3}$ the nano rods are dumbbell in shape having sharp tips with open ends (Fig. 5b). The particle size is found to be in the range $25-90 \mathrm{~nm}$. The selected area electron diffraction patterns (SAED) of the products (Fig. $5 \mathrm{c}$ and d) show highly crystalline in nature. The nominal composition of $\mathrm{Nd}_{2} \mathrm{O}_{3}$ synthesized by both the methods was studied using energy dispersive $\mathrm{X}$-ray analysis.
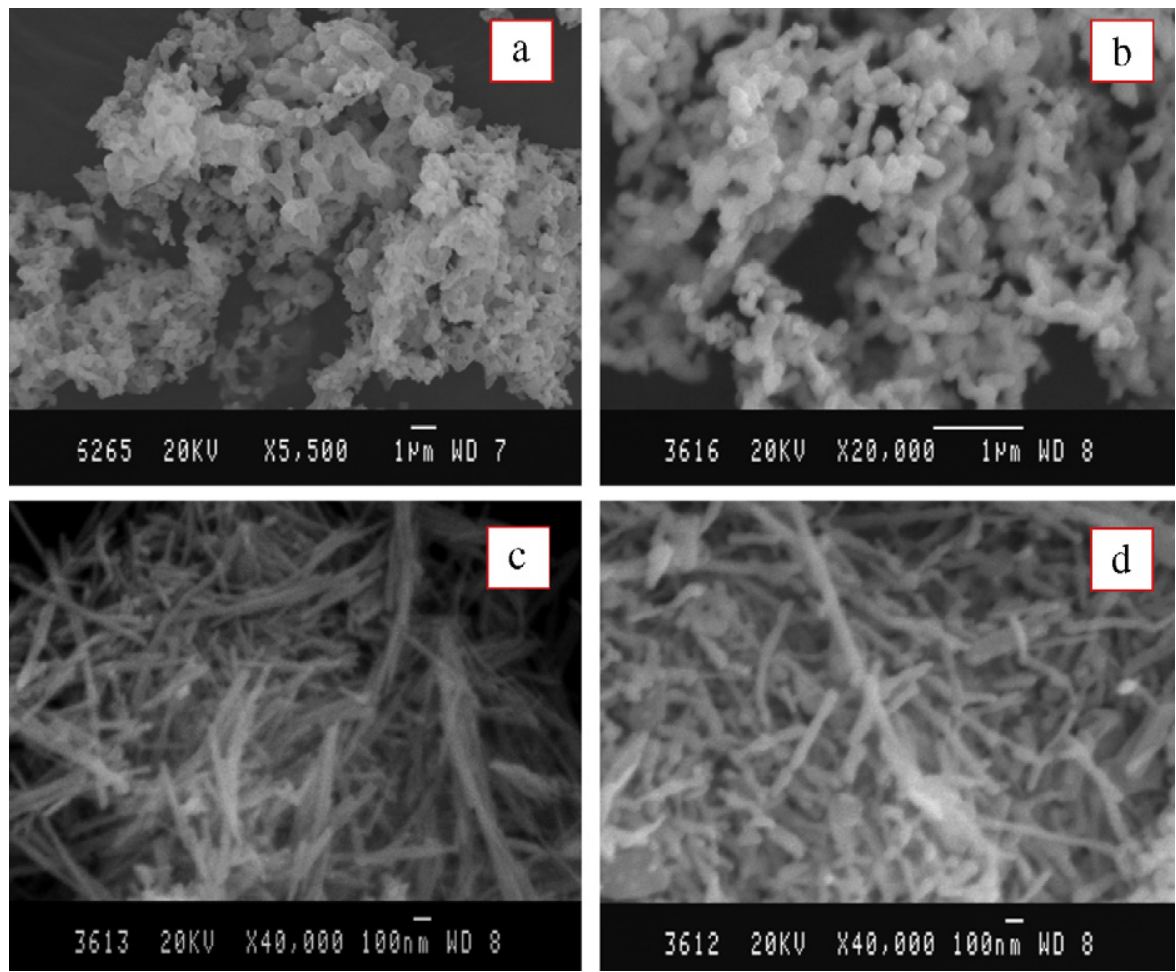

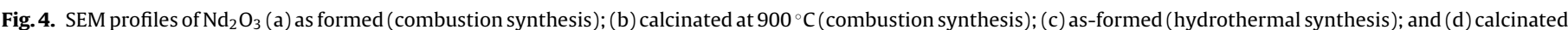
at $900^{\circ} \mathrm{C}$ (hydrothermal synthesis). 

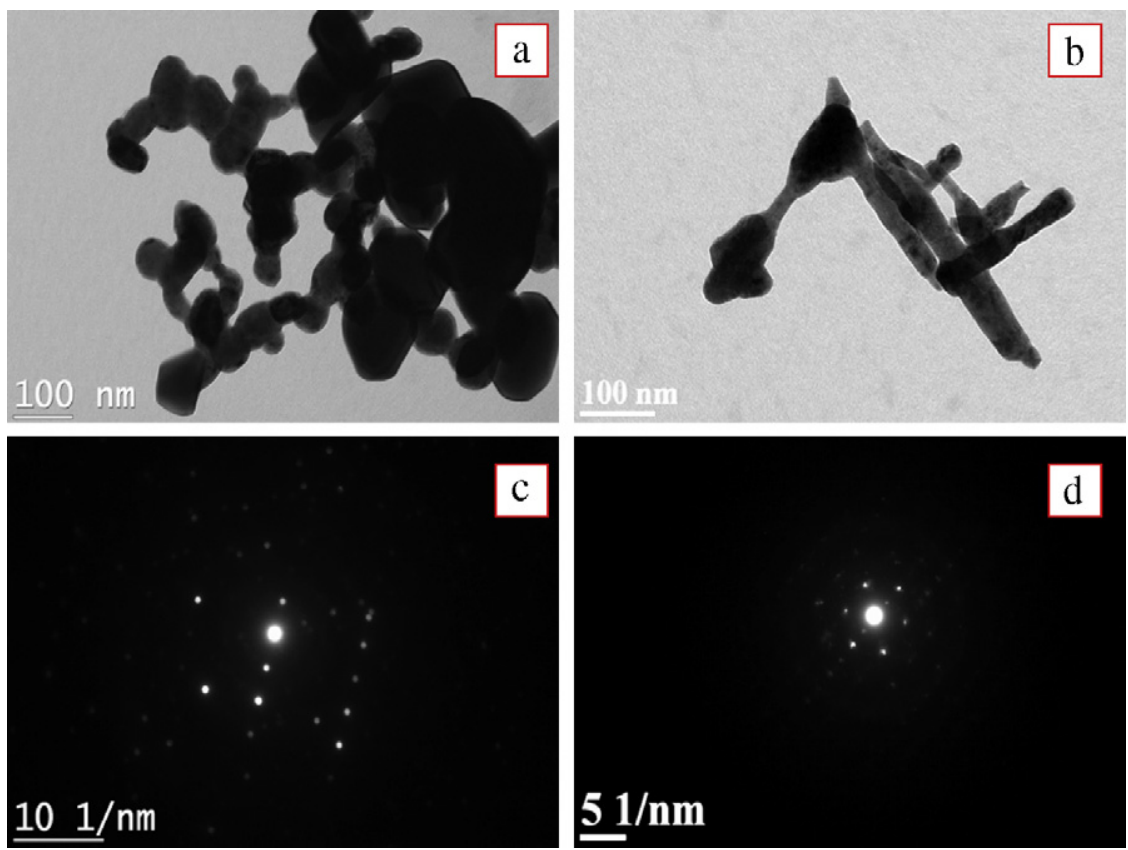

Fig. 5. TEM images of $\mathrm{Nd}_{2} \mathrm{O}_{3}$ (a) combustion synthesis; (b) hydrothermal synthesis; (c) SAED-combustion and (d) SAED-hydrothermal.

Fig. 6 shows the FTIR spectra of $\mathrm{Nd}_{2} \mathrm{O}_{3}$ phosphor prepared by solution combustion and hydrothermal methods. The peaks at 407 and $670 \mathrm{~cm}^{-1}$ in calcined samples (Fig. $6 \mathrm{~b}$ and d) represent the characteristic metal-oxygen ( $\mathrm{Nd}-\mathrm{O})$ vibrations. A sharp peak at $3615 \mathrm{~cm}^{-1}$ in Fig. $6 \mathrm{c}$ represents $\mathrm{M}-\mathrm{OH}$ peak. The band between 3500 and $3800 \mathrm{~cm}^{-1}$ is due to the $\nu(\mathrm{O}-\mathrm{H})$ vibration of $\mathrm{H}_{2} \mathrm{O}$ absorbed by $\mathrm{Nd}_{2} \mathrm{O}_{3}$ phosphor. The band between 1350 and $1500 \mathrm{~cm}^{-1}$ is assigned to the carbonate peaks and these bands are observed in all the spectra, except in calcined sample of hydrothermal product (Fig. 6d). The small peaks at 598, 625 and $1066-1200 \mathrm{~cm}^{-1}$ (Fig. 6d) represent traces of $\mathrm{M}-\mathrm{OH}$ present in the hydrothermally derived final product and these are unidentified from PXRD profiles.

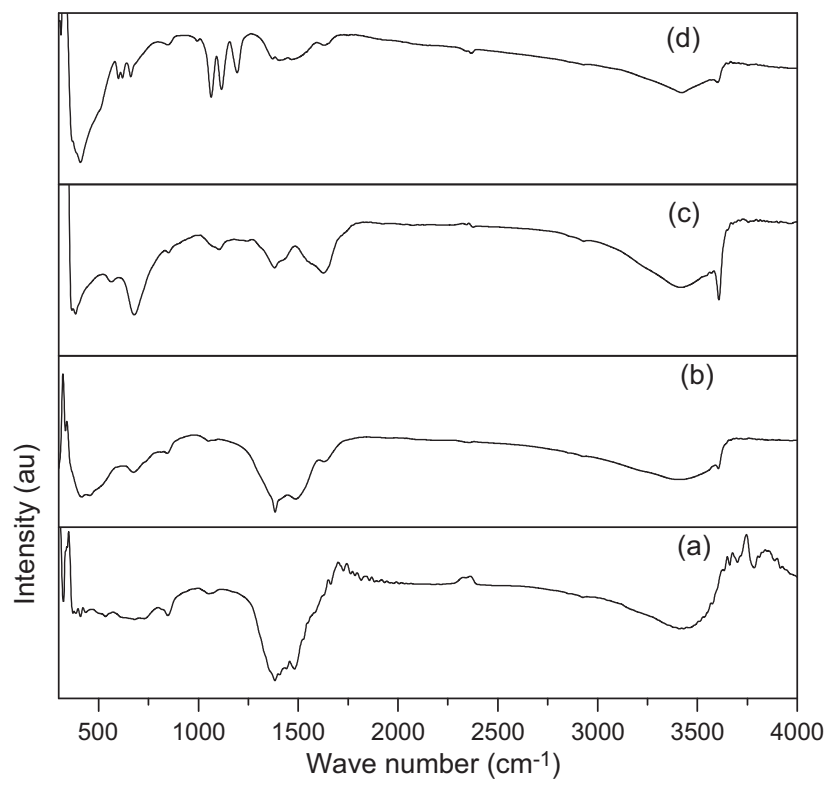

Fig. 6. FTIR spectra of $\mathrm{Nd}_{2} \mathrm{O}_{3}$ (a) as formed (combustion synthesis); (b) calcined at $900{ }^{\circ} \mathrm{C}$ (combustion synthesis); (c) as-formed (hydrothermal synthesis); and (d) calcined at $900^{\circ} \mathrm{C}$ (hydrothermal synthesis).
Fig. 7a-d shows Raman spectra of combustion and hydrothermal synthesized $\mathrm{Nd}_{2} \mathrm{O}_{3}$ phosphor recorded with an excitation wavelength of $633 \mathrm{~nm}$ laser beam. According to factor group theory 22 active Raman modes have been predicted for the $\mathrm{Nd}_{2} \mathrm{O}_{3}$ A-type structure [22]. The major peaks in both the samples observed are assigned to $\mathrm{F}_{\mathrm{g}}$ mode and combination of $A_{\mathrm{g}}+E_{\mathrm{g}}[23,24]$ modes. It is observed that in combustion synthesized sample, Raman peaks are broader and shifted to higher wave number side by about $9 \mathrm{~nm}$ when compared to hydrothermal synthesized sample. This frequency shift and broadening of Raman peaks might be attributed to decrease in particle size to nanometer scale [25]. Further, it is observed that the number of active Raman modes is less in hydrothermal method when compared to combustion method. This is attributed to different synthesis methods.

The UV-visible absorption spectrum of combustion synthesized $\mathrm{Nd}_{2} \mathrm{O}_{3}$ phosphors calcined at $900{ }^{\circ} \mathrm{C}$ for $3 \mathrm{~h}$ exhibit a broad and prominent absorption band with maximum at $\sim 250 \mathrm{~nm}$ along with weak absorption bands at $\sim 380,580,750$ and $810 \mathrm{~nm}$.

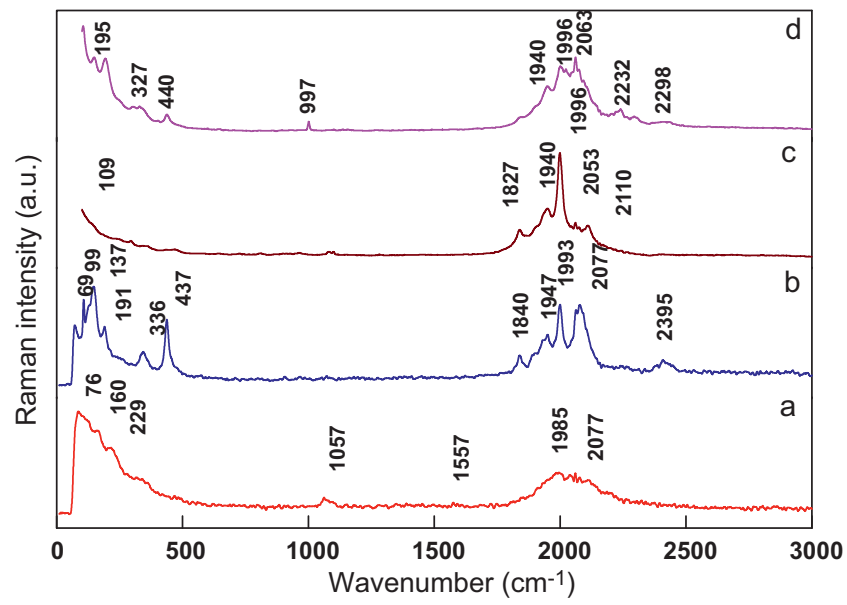

Fig. 7. Raman spectra of $\mathrm{Nd}_{2} \mathrm{O}_{3}$ (a) as formed (combustion synthesis); (b) calcinated at $900{ }^{\circ} \mathrm{C}$ (combustion synthesis); (c) as-formed (hydrothermal synthesis); and (d) calcinated at $900^{\circ} \mathrm{C}$ (hydrothermal synthesis). 


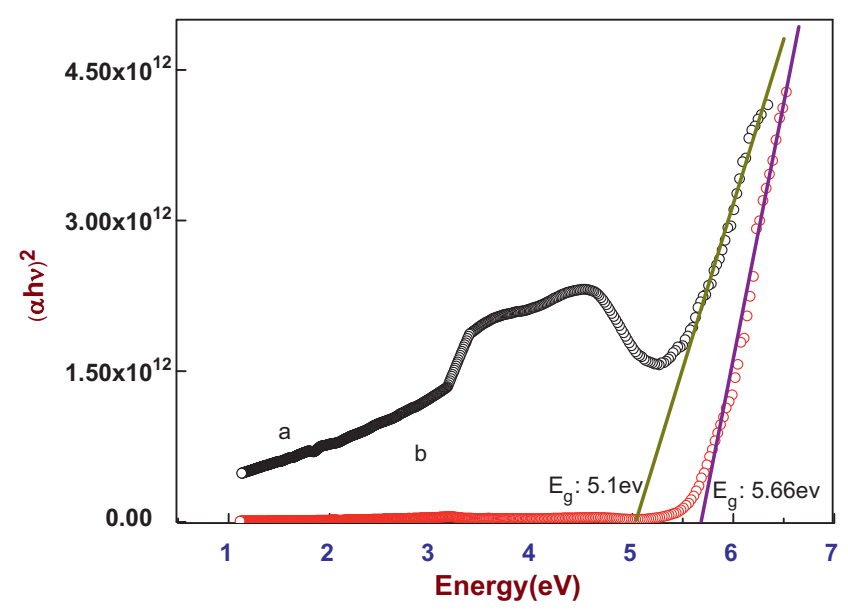

Fig. 8. Energy band gap of $\mathrm{Nd}_{2} \mathrm{O}_{3}$ (a) as formed (combustion synthesis) and (b) calcinated at $900^{\circ} \mathrm{C}$ (combustion synthesis).

For hydrothermal synthesized phosphor a sharp and prominent absorption band with a maximum at $\sim 235 \mathrm{~nm}$ along with weak absorption bands at 610,760 and $816 \mathrm{~nm}$ have been observed. The maximum absorption, which can arise due to transition between valence band and conduction band [26]. The weak absorption in the UV-visible region is expected to arise from transitions involving extrinsic states such as surface traps or defect states or impurities [27]. Smaller size particles are found to have high surface to volume ratio. This results in increase of defects distribution on the surface of nanomaterials. Thus the lower is the particle size, nanomaterials exhibit strong and broad absorption bands [28]. In combustion synthesized $\mathrm{Nd}_{2} \mathrm{O}_{3}$ the particle size is in nanometer size which results high surface to volume ratio; as a result, an increase of defects distribution on the surface of the nanomaterials.

The optical energy band gap $\left(E_{g}\right)$ of combustion and hydrothermal synthesized $\mathrm{Nd}_{2} \mathrm{O}_{3}$ were calculated using Tauc relation [29]:

$(\alpha h v)^{2}=c\left(h v-E_{\mathrm{g}}\right)$

where $h v$ is the photon energy and $\alpha$ is the absorption edge. The absorption co-efficient $\alpha$ was calculated from the optical absorption spectra. The direct band gap energy can be determined by plotting $(\alpha h v)^{2}$ vs $h v$ in the high absorption range followed by extrapolating the linear region of the plots to $(\alpha h v)^{2}=0$ and is shown in Fig. 8 for combustion synthesis and for hydrothermal synthesis it is shown in Fig. 9 respectively. The analysis of the present

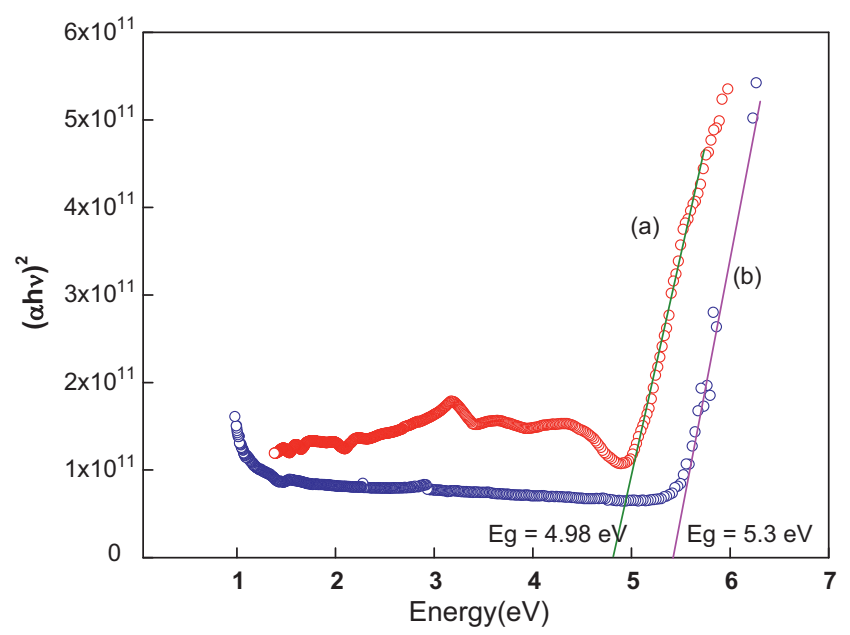

Fig. 9. Energy band gap of $\mathrm{Nd}_{2} \mathrm{O}_{3}$ (a) as-formed (hydrothermal synthesis) and (b) calcinated at $900^{\circ} \mathrm{C}$ (hydrothermal synthesis).

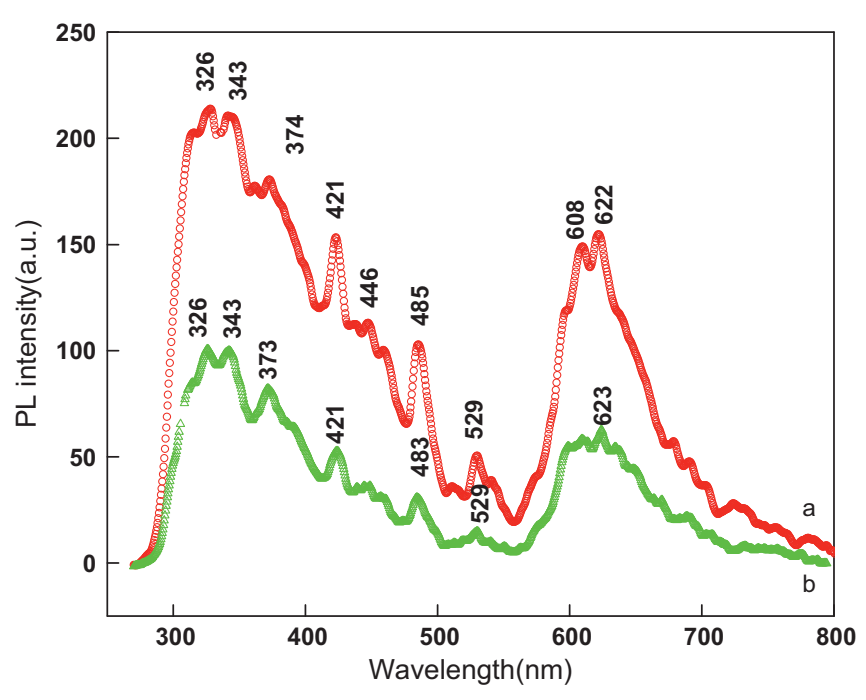

Fig. 10. PL spectra of $\mathrm{Nd}_{2} \mathrm{O}_{3}$ calcinated at $900{ }^{\circ} \mathrm{C}$ for $3 \mathrm{~h}$ (a) combustion synthesis and (b) hydrothermal synthesis.

data shows that the plots of $(\alpha h v)^{2}$ against $h v$ give linear relation and best fit for Eq. (3) with $n=2$. This indicates that allowed direct transitions are responsible for the inter band transitions in $\mathrm{Nd}_{2} \mathrm{O}_{3}$ nanocrystalline samples [30]. The optical energy band gap for combustion and hydrothermal $\mathrm{Nd}_{2} \mathrm{O}_{3}$ are found to be 5.66 and $5.30 \mathrm{eV}$ respectively. It is observed that optical energy band gap is found to be widened in combustion synthesized samples when compared to hydrothermal method. This is attributed to particle size effect. The nanomaterials have large surface to volume ratio as a result the formation of voids on the surface as well as inside the agglomerated particles. Such voids can cause fundamental absorption in the UV wavelength range [31].

Fig. 10 shows the photoluminescence spectra of (a) combustion and (b) hydrothermal synthesized $\mathrm{Nd}_{2} \mathrm{O}_{3}$ phosphors. The PL spectra shows a series of emission bands at $\sim 326-373 \mathrm{~nm}$ (UV), 421-485 nm (blue) and 529-542 nm (green) and $622 \mathrm{~nm}$ (red). The broad emission band in the UV region is attributed to the singly ionized oxygen vacancies in $\mathrm{Nd}_{2} \mathrm{O}_{3}$ [31]. The broad UV emission can also arise due to radiative recombination of photo-generated hole with an electron occupying the oxygen vacancy [32]. The blue, green and red emissions have been suggested mainly due to the presence of surface defects like Schottky and Frankel exist in the lattice. The UV, blue, green and red emission in the PL spectrum indicates that $\mathrm{Nd}_{2} \mathrm{O}_{3}$ nanocrystals are promising materials for high performance optical materials and white light emitting diodes (LED).

\section{Conclusions}

A-type $\mathrm{Nd}_{2} \mathrm{O}_{3}$ (spherical and rod type) nanocrystalline phosphors have been successfully prepared by solution combustion and hydrothermal methods respectively. By Rietveld refinement the lattice parameters $a=3.8312(1)(\AA) ; c=6.0017(3)$ and cell volume $76.29(7)(\AA)^{3}$ have been evaluated which confirm that $\mathrm{Nd}_{2} \mathrm{O}_{3}$ has a hexagonal structure. In combustion synthesized powders, the particles are spherical in shape and essentially consists of different sizes varying from 20 to $100 \mathrm{~nm}$. In hydrothermal synthesized $\mathrm{Nd}_{2} \mathrm{O}_{3}$ the nano rods are dumbbell in shape having sharp tips with open ends. The particle size is found to be in the range $25-90 \mathrm{~nm}$. It is observed that in combustion synthesized phosphor, the Raman peaks are broader and shifted to higher wavelength side by $\sim 9 \mathrm{~nm}$ when compared to hydrothermal method. The frequency shift and broadening of Raman peaks might be attributed to decrease in 
particle size to nanometer scale. The optical energy band gap in combustion and hydrothermal methods were found to be 5.66 and $5.33 \mathrm{eV}$ respectively. It is observed that the optical band gap is widened in combustion-synthesized materials when compared to hydrothermal method. This is attributed to particle size effect. The PL spectrum shows a series of emission bands at $\sim 326-373 \mathrm{~nm}$ (UV), 421-485 nm (blue), 529-542 nm (green) and $622 \mathrm{~nm}$ (red). From the two synthesis methods of $\mathrm{Nd}_{2} \mathrm{O}_{3}$, low-temperature combustion route is safe, simple and rapid for the production of fine and homogeneous powders and useful for large scale production for phosphor in display technology.

\section{Acknowledgement}

The author (H.N. Nagabhushana), Thanks to Dr. S. C. Sharma, Vice chancellor, Tumkur university, Tumkur for constant encouragement and support. The authors are grateful to TEQIP Lab of M.S. Ramaiah Institute of technology, Bangalore for providing facilities for preparation of materials.

\section{References}

[1] G. Adachi, N. Imanaka, Chem. Rev. 98 (1998) 1479.

[2] R. Bazzi, M.A. Flores-Gonzalez, C. Louis, K. Lebbou, C. Dujardin, A. Brenier, W. Zhang, O. Tillement, E. Bernstein, J. Lumin. 102/103 (2003) 445

[3] A.G. Dedov, A.S. Loktev, I.I. Moiseev, A. Aboukais, J.F. Lamonier, I.N. Filimonov, Appl. Catal. A 245 (2003) 209.

[4] S. Pengpanich, V. Mecyoo, T. Rirksomboon, J. Chem. Eng. Jpn. 38 (2005) 49.

[5] E.J. Bosze, J. Mckittrick, G.A. Hirata, Mater. Sci. Eng. B 97 (2003) 265

[6] J.J. Kingsley, K.C. Patil, Mater. Lett. 6 (1998) 427.

[7] J. Mckittrick, L.E. Shea, C.F. Bacalski, E.J. Bosze, Displays 19 (1999) 169.
[8] Y.P. Fu, S.B. Wen, C.S. Hsu, J. Alloys Compd. 458 (2008) 318.

[9] L. Kepinski, M. Zawadzki, W. Mista, Solid State Sci. 6 (2004) 1327.

[10] M. Zawadzki, L. Kepinski, J. Alloys Compd. 380 (2004) 255.

[11] G. Jia, K. Liu, Y. Zheng, Y. Song, M. Yang, H. You, J. Phys. Chem. C 113 (2009) 6050.

[12] T. Sreethawong, S. Chavadej, S. Ngamsinlapasathian, S. Yoshikawa, Solid State Sci. 10 (2008) 20

[13] Miroslaw Zawadzki, J. Alloys Compd. 451 (2008) 297.

[14] W. Que, C.H. Kam, Y. Zhou, Y.L. Lam, Y.C. Chan, J. Appl. Phys. 90 (2001) 4865.

[15] W. Yang, Y. Qi, Y. Ma, X. Li, X. Guo, M. Chen, Mater. Chem. Phys. 84 (2004) 52

[16] S.V. Chavan, S.N. Achary, A.K. Tyagi, J. Alloys Compd. 441 (2007) 332.

[17] B.M. Nagabhushana, Ph.D. Thesis, Bangalore University, 2008.

[18] J. Rodriguez-Carvajal, Fullproof 2000: A Program for Rietveld, profile matching and Integrated Intensity Refinements for X-ray and Neutron data. Version 1.6, Laboratoire Leon Brillounin, Gif sur Yvette, France, 2009.

[19] R.W.G. Wyckoff, Crystal Structures, vol. 2, Interscience, New York, 1964, pp. 4-5.

[20] G. Liu, G. Hong, J. Wang, X. Dong, J. Alloys Compd. 432 (2007) 200

[21] G. Blasse, B.C. Grabmaier, Luminescent Materials, Springer, Berlin, 1994

[22] N. Dilawar, S. Mahrotra, D. Varandani, B.V. Kumaraswamy, S.K. Halder, A.K. Bandyopadhyay, Mater. Charact. 59 (2008) 462.

[23] A. Ubaldini, M.M. Carnasciali, J. Alloys Compd. 454 (2008) 374.

[24] Y. Xu, J. Wu, W. Sun, D. Tao, L. Yang, Z. Song, S. Weng, Z. Xu, R.D. Soloway, D. Xu, G. Xu, J. Eur. Chem. 23 (2002) 8.

[25] T. Bilajan, S. Roncevic, Z. Meic, K. Kovac, Chem. Phys. Lett. 395 (2004) 246

[26] L.K. Pan, Q. Sunchang, C.M. Li, J. Phys. Chem. B 108 (2004) 3404.

[27] H.Q. Cao, X.Q. Qiu, B. Luo, Y. Liang, Y.H. Zhang, R.Q. Tan, M.J. Zhao, Q.M. Zhu, Adv. Funct. Mater. 14 (2004) 243

[28] A. Emeline, G.V. Kataeva, A.S. Litke, A.V. Rudakova, V.K. Ryabchuk, N. Serpone, Langmuir 14 (1998) 5011.

[29] C. Pandurangappa, B.N. Lakshminarasappa, B.M. Nagabhushana, J Alloys Compd. 489 (2010) 592.

[30] J. Tauc, F. Abeles, Optical Properties of Solids, North-Holland, Amsterdam, 1970.

[31] N. Salah, S.S. Habib, Z.H. Khan, S.A. Hamedi, S.P. Lochab, J. Lumin. 129 (2009) 192.

[32] G.A. Kumar, C.W. Chen, J. Ballato, R.E. Riman, Chem. Mater. 19 (2007) 1523. 